\section{An efficient method for}

\section{acclimatization: in vitro hardening of tissue culture-raised tea plants (Camellia sinensis (L.) O. Kuntze)}

\author{
Niladri Bag ${ }^{1,2, *}$, Lok Man S. Palni ${ }^{1,3}$ and \\ Shyamal Kumar Nandi ${ }^{1}$ \\ ${ }^{1}$ G.B. Pant National Institute of Himalayan Environment and \\ Sustainable Development, Kosi-Katarmal, Almora 263 643, India \\ ${ }^{2}$ Present address: Sikkim University, Department of Horticulture, \\ 6th Mile, Samdur, P.O. Tadong, Gangtok 737 102, India \\ ${ }^{3}$ Present address: Graphic Era Deemed to be University, Clement Town, \\ Dehradun 248 002, India
}

In the 21st century while there is all-round development in every sphere of science and technology, a major limitation in micropropagation technology stil remains; a large number of plantlets of several species die during hardening and $e x$ vitro transfer. In the present study, introducing an in vitro incubation period in plant growth regulator (PGR)-free medium followed by root induction of micropropagated tea shoots (Camellia sinensis (L.) O. Kuntze) and increasing it to 12 weeks instead of the usual 4 weeks gave excellent results. Secondly, cultures were grown in larger vessels, i.e. in $500 \mathrm{ml}$ conical flasks in place of normal $250 \mathrm{ml}$ conical flasks. Interestingly, prolonged incubation (12 weeks) significantly enhanced overall growth, i.e. length, stem girth, leaf number and leaf area of plantlets. The use of larger-sized culture flask also positively influenced growth. The abovementioned two simple modifications in culture conditions improved overall growth of plantlets. Also, plantlets raised through prolonged culture were acclimatized with $94 \%$ survival efficiency in comparison to $46 \%$ with normal culture period, and showed improved growth performance on transfer to soil in the nursery, irrespective of the culture vessel size.

Keywords: Acclimatization, in vitro hardening, lab-toland transfer, prolonged culture, tea micropropagation.

IN recent years, along with the progress in overall scientific developments, micropropogation technology has also progressed, and is considered as an efficient method for the production of a large number of morphologically, physiologically and genetically identical clonal plants within a short time, irrespective of seasonal and other factors. It has, however, some limitations; for example, sufficient number of micropropagated plantlets of several species fail to survive during lab-to-land transfer. Therefore, acclimatization is a significantly important and critical step for the transfer of micropropagated plantlets to the field. Anatomical and physiological transition is also important for hardening while transferring plantlets

\footnotetext{
*For correspondence. (e-mail: niladribag@rediffmail.com)
}

from in vitro to ex vitro environment ${ }^{1}$. Several reports have shown that poor survival of in vitro-raised plants under ex vitro conditions is mainly due to soft green stem, non-functional stomata, poor cuticular development, excessive transpiration, less-developed root system and their susceptibility to pathogens ${ }^{2,3}$. In the course of hardening, the in vitro micropropagated plants slowly overcome these abnormalities and adapt to ex vitro field conditions.

In case of tea micropropagation, some reports have mentioned the conditions needed for transfer of plantlets from laboratory to soil. Among them, some have obtained plantlets by somatic embryogenesis or regenerated adventitious shoots followed by rooting ${ }^{4}$. Few researchers used a mixture of soil and vermiculite; soil-sand mixture $(3: 1)$; few have used mist in a greenhouse for successful acclimatization of micropropagated plantlets ${ }^{4-6}$. Another study reported that tea plantlets regenerated from cotyledon callus grew vigorously in soil, but were different considerably in terms of their morphology from that of naturally grown plants in the field ${ }^{7}$. In 1990, a study reported $20 \%$ survival when plants were transferred directly to garden soil, but following the use of peat and soil mixture (1:1) survival was increased to $70 \%$ (ref. 8). Due to the problems associated with efficient rooting of tea microshoots and subsequent hardening, tissue-culture protocols have thus far not been exploited commercially ${ }^{9,10}$. The most successful study so far has achieved survival of micropropagated plants from $88 \%$ to $100 \%$, using antagonistic bacteria isolated from the tea rhizosphere soil obtained from different geographical locations in India, against $36 \%$ to $52 \%$ in control plantlets ${ }^{2}$. The bacteria were used in soil for biological hardening during lab-to-land transfer under greenhouse conditions. Therefore, the present study was designed to achieve successful hardenng of tissue culture-raised tea plantlets, ready for transplantation with high survival efficiency, using simple modifications in the physical factors of in vitro cultures.

Initially immature cotyledons were used as explants to obtain a large number of microshoots of tea (Camellia sinensis (L.) O. Kuntze) ${ }^{4}$. Shoots were multiplied and maintained on Murashige and Skoog's (MS) medium ${ }^{10}$ with 5.0 $\mu \mathrm{M}$ 6-benzyl amino purine (BAP) plus $1.0 \mu \mathrm{M}$ indole-3-butyric acid (IBA) and solidified with $0.2 \%$ phytagel (w/v, Sigma, USA) ${ }^{10}$. After 4-5 weeks of transfer to multiplication medium, individual shoots of about 25$30 \mathrm{~mm}$ height were separated and transferred to the rooting medium.

For rooting, the green $25-30 \mathrm{~mm}$ long tea microshoots were further transferred onto one-third strength MS medium containing $25.0 \mu \mathrm{M} \alpha$-naphthalene acetic acid (NAA) and $50.0 \mathrm{mM}$ sucrose. $\mathrm{pH}$ of the medium was maintained at 5.5 , gelled with $0.2 \%$ phytagel for 10 days, after which the contents were then transferred to fresh one-third strength MS medium and kept at $25^{\circ} \mathrm{C}$ under $40 \mu \mathrm{mol} \mathrm{m} \mathrm{m}^{-1}$ light $^{11}$. 


\section{RESEARCH COMMUNICATIONS}

In this experiment, two culture vessels of different size, i.e. 250 and $500 \mathrm{ml}$ conical flasks were used to observe the effect of vessel volume on the in vitro growth of plantlets, and their survival during acclimatization and subsequent transfer to soil. Duration of the culture period on plant growth regulator (PGR)-free medium, following the root induction treatment, was increased to 12 weeks instead of the usual 4 weeks. This was achieved by increasing the length of incubation period to 12 weeks and by providing larger space to micropropagated plants under in vitro conditions. Initially microshoots were kept on one-third strength MS medium containing $25.0 \mu \mathrm{M}$ NAA for 10 days, and then shifted to one-third strength on MS medium without any PGR. Two sets of treated shoots were transferred and cultured on one-third strength MS medium having $50 \mathrm{mM}$ sucrose, either in $250 \mathrm{ml}$ or $500 \mathrm{ml}$ conical flasks containing equal amount of $60 \mathrm{ml}$ medium solidified with $0.2 \%$ phytagel $(\mathrm{w} / \mathrm{v})$. After 12 weeks from the date of root induction, the plantlets were transplanted to soil in root trainer tray in the greenhouse.

Well-rooted plants grown in culture were taken out from the flasks, washed thoroughly with running tap water to remove medium attached to the roots, and transplanted into root trainer tray containing sterilized soil and sand mixture (3:1, v/v; pH 5.4). To maintain adequate moisture, a transparent plastic covering was placed on top of each tray during hardening, in the greenhouse $\left(25^{\circ} \pm 3{ }^{\circ} \mathrm{C} ; 50 \%\right.$ shade $)$ at the G.B. Pant National Institute of Himalayan Environment and Sustainable Development nursery at Katarmal, Almora. Watering was done at 15 days interval and the plastic covering the tray was removed after a month; and then the plants were allowed to grow in the greenhouse under natural light, temperature and humidity.

A total of 30 leaves (ten per treatment with three replicates) for each treatment were collected to determine fresh, turgid and dry weight of leaves. For this, sample collection was done at 9.30 am and immediately the fresh weight $\left(F_{\mathrm{w}}\right)$ was recorded. These leaves were kept in deionized water (Milli-Q) for $12 \mathrm{~h}$ in the dark, and then turgid weight $\left(T_{\mathrm{w}}\right)$ of the leaves was measured after removal of excess water using tissue paper. Following the measurement of leaf area (leaf area meter; model LI-3000, LI-COR, USA), the same sets of leaves were kept in a hot-air oven at $80^{\circ} \mathrm{C}$ for $48 \mathrm{~h}$ and dry weight $\left(D_{\mathrm{w}}\right)$ was recorded. Specific mass of leaves was determined by dividing the leaf dry weight by total leaf area. Relative water content (RWC) of leaves was estimated using the following equation: RWC $(\%)=\left(F_{\mathrm{w}}-D_{\mathrm{w}}\right) /$ $\left(T_{\mathrm{w}}-D_{\mathrm{w}}\right) \times 100$ (ref. 12).

For leaf anatomy, hand-cut sections of leaf samples were dehydrated in different serial concentrations of ethanol. Sections were stained with safranin $(1 \%, \mathrm{w} / \mathrm{v}$, Sigma, USA) and light green $(0.5 \%, \mathrm{w} / \mathrm{v}, \mathrm{Sigma}, \mathrm{USA})$, and mounted in DPX (Hi-Media, India) for microscopic examinations.

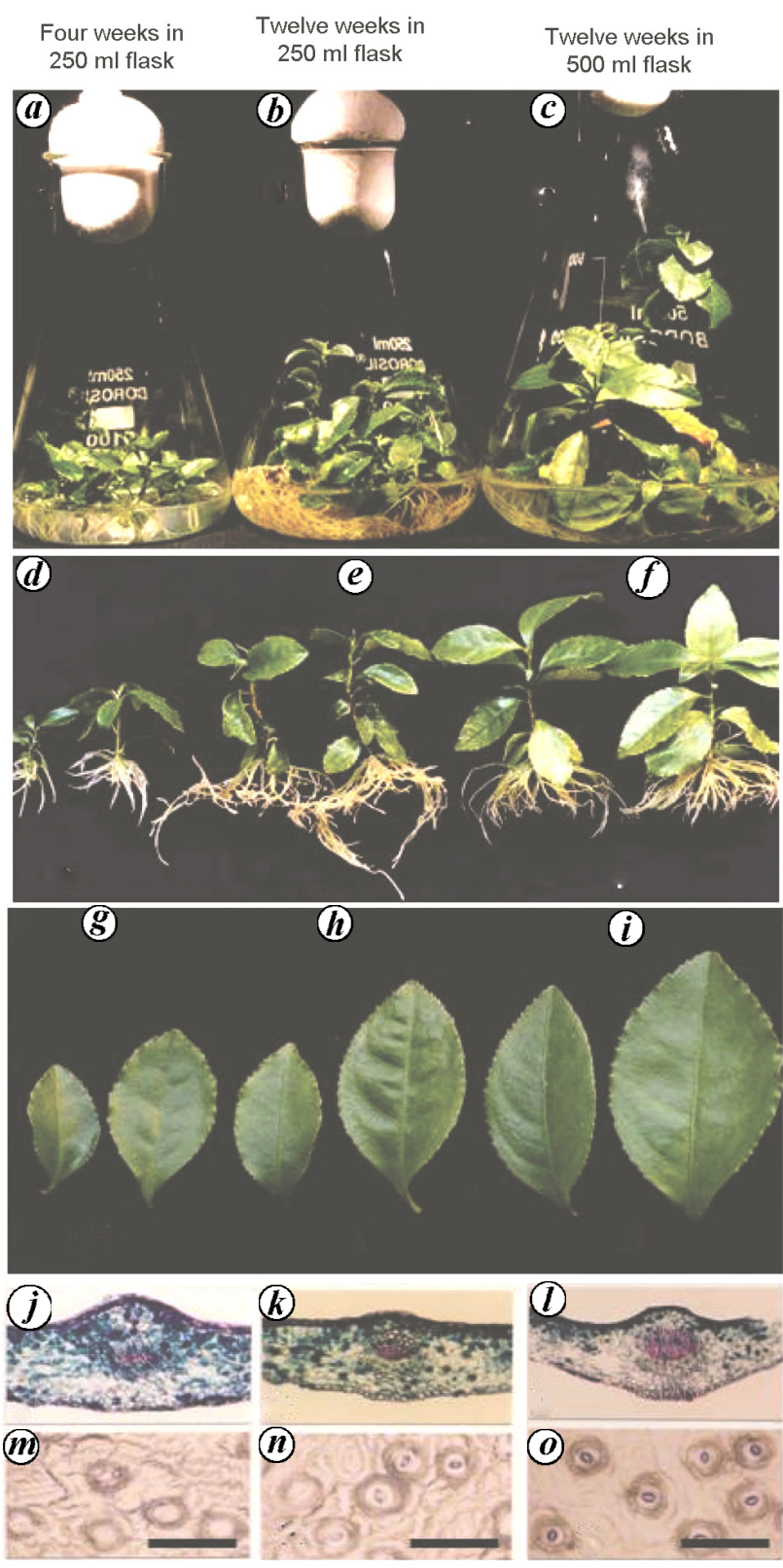

Figure 1. Comparison of in vitro hardened plants grown under varied cultural conditions in terms of some morphological, physiological and anatomical parameters. $\boldsymbol{a}-\boldsymbol{c}$, Plantlets grown for $(\boldsymbol{a}) 4$ weeks in $250 \mathrm{ml}$ conical flask, (b) 12 weeks in $250 \mathrm{ml}$ conical flask and (c) 12 weeks in $500 \mathrm{ml}$ conical flask. $\boldsymbol{d}-\boldsymbol{f}$, Plantlets taken out of the conical flasks showing varied morphological features: $(\boldsymbol{d})$ grown for 4 weeks in $250 \mathrm{ml}$ conical flask, $(\boldsymbol{e})$ grown for 12 weeks in $250 \mathrm{ml}$ conical flask and $(\boldsymbol{f})$ grown for 12 weeks in $500 \mathrm{ml}$ conical flask. $\boldsymbol{g}$-i, Representative leaves of in vitro-raised plants: $(g)$ grown for 4 weeks in $250 \mathrm{ml}$ conical flask, (h) grown for 12 weeks in $250 \mathrm{ml}$ conical flask and (i) grown for 12 weeks in $500 \mathrm{ml}$ conical flask. $\boldsymbol{j}-\boldsymbol{l}$, Transverse section of leaves $($ bar $=50 \mu \mathrm{m})$ of in vitro-raised plantlets: $(j)$ 4-week-old rooted plantlets grown in $250 \mathrm{ml}$ conical flask showing thick lamina with larger parenchymatous cells; $(\boldsymbol{k}) 12$-week-old rooted plantlets grown in $250 \mathrm{ml}$ conical flask showing less developed vascular system and $(\boldsymbol{l})$ 12 -week-old rooted plantlets grown in $500 \mathrm{ml}$ conical flask showing well-developed vascular system. $\boldsymbol{m}-\boldsymbol{o}$, Stomata $(\mathrm{bar}=20 \mu \mathrm{m})$ of $(\boldsymbol{m}) 4$ week-old rooted plantlets grown in $250 \mathrm{ml}$ conical flask showing low frequency and larger openings; $(\boldsymbol{n})$ of 12-week-old rooted plantlets grown in $250 \mathrm{ml}$ conical flask showing larger stomata, and (o) 12 week-old rooted plantlets grown in $500 \mathrm{ml}$ conical flask showing normal appearance of stomata. 
Table 1. Comparison of in vitro hardened plants in terms of selected morphological, anatomical and physiological parameters at the time of transfer to soil

\begin{tabular}{|c|c|c|c|c|}
\hline Parameters & $\begin{array}{l}\text { Four-week-old plants } \\
\text { grown in } 250 \mathrm{ml} \\
\text { conical flasks } \pm \mathrm{SE}\end{array}$ & $\begin{array}{l}\text { Twelve-week-old } \\
\text { plants grown in } 250 \mathrm{ml} \\
\text { conical flasks } \pm \mathrm{SE}\end{array}$ & $\begin{array}{l}\text { Twelve-week-old } \\
\text { plants grown in } 500 \mathrm{ml} \\
\text { conical flasks } \pm \mathrm{SE}\end{array}$ & LSD \\
\hline Height (cm) & $3.13 \pm 0.14$ & $3.54 \pm 0.15$ & $4.41 \pm 0.29$ & 0.62 \\
\hline Stem girth (mm) & $0.61 \pm 0.05$ & $1.25 \pm 0.06$ & $1.52 \pm 0.08$ & 0.20 \\
\hline Leaf no. per plant & $4.07 \pm 0.35$ & $8.60 \pm 0.78$ & $11.04 \pm 1.11$ & 2.47 \\
\hline Leaf area/plant $\left(\mathrm{cm}^{2}\right)$ & $4.91 \pm 0.46$ & $16.11 \pm 0.95$ & $21.34 \pm 1.95$ & 4.41 \\
\hline Leaf thickness $(\mu \mathrm{m})$ & $195.78 \pm 4.72$ & $183.21 \pm 7.41$ & $170.64 \pm 5.82$ & 19.00 \\
\hline Stomatal frequency $\left(\right.$ no. $\left./ \mathrm{mm}^{2}\right)$ & $238.71 \pm 6.80$ & $254.45 \pm 8.30$ & $260.74 \pm 2.97$ & 22.15 \\
\hline \multicolumn{5}{|l|}{ Stomata size } \\
\hline Length $(\mu \mathrm{m})$ & $36.56 \pm 0.93$ & $39.87 \pm 0.28$ & $37.49 \pm 0.17$ & 1.96 \\
\hline Width $(\mu \mathrm{m})$ & $30.14 \pm 0.40$ & $31.93 \pm 0.18$ & $31.83 \pm 0.55$ & 1.40 \\
\hline $\begin{array}{l}\text { Relative water content of leaves }(\%) \\
\quad(\text { RWC) }\end{array}$ & $96.52 \pm 0.37$ & $96.00 \pm 0.45$ & $96.18 \pm 0.28$ & 1.29 \\
\hline Specific leaf mass & $3.87 \pm 0.09$ & $4.95 \pm 0.07$ & $4.71 \pm 0.14$ & 0.36 \\
\hline
\end{tabular}

SE, Standard error. Each treatment consists of five replicates. LSD, Least significant difference.

Stomatal frequency and size of stomata measured in the 3rd leaf from the top for each plant, were determined using impressions of both the surfaces of leaves (adaxial and abaxial) and by taking random observations under a light microscope (400X magnification, Labophot-2, Nikon, Japan).

In vitro micropropagation is being used extensively for mass multiplication of many plant species, in numerous commercial laboratories across the world (orchid cultivation can be regarded as a success of this technique). However, use of this technology is still limited for many important plant species due to high mortality during transfer from the laboratory to soil, with several associated problems. Hardening of in vitro-raised plantlets may require special infrastructure, like a greenhouse, misting chamber, etc. and is a time-consuming, labour intensive procedure, adding to the production costs. In vitro-raised plants are inclined to transplantation shock resulting in high mortality during acclimatization of micropropagated plants ${ }^{12,13}$. The efficient acclimatization of in vitro micropropagated plants is the ultimate goal in successful micropropagation. Results of the present study show simple modification in culture conditions, i.e. prolonged incubation period for 12 weeks that resulted in enhanced overall growth improvement of plantlets under in vitro conditions (Table 1). As a result, stems of microshoots showed more secondary growth with larger diameter and turned yellowish to brown (Figure $1 e$ and $f$ ). Leaf number as well as size also improved considerably (Figure $1 e$ and $f$ ). The root system was also found to become more vigorous with profuse branching upon prolonged incubation. With regard to the two different sized conical flasks used (250 and $500 \mathrm{ml})$, better growth was recorded in the larger flask (Table 1). Leaves of the tissue cultureraised plantlets following prolonged incubation in $500 \mathrm{ml}$ conical flasks were broader than those cultured in $250 \mathrm{ml}$ conical flasks (Figure $1 i$ ). This may enhance the overall physiological strength of those plantlets. However, there was no or little difference in the leaf thickness of plantlets in the two cases (Figure $1 j-l$ ). Stomatal frequency and specific leaf mass were also found to be significantly higher in plantlets following prolonged incubation in comparison to that of normal 4-week-culture. No significant difference was observed in stomatal size and per cent RWC for plantlets grown under different cultural conditions (Table 1).

It was also recorded that for tissue culture-raised plantlets following prolonged incubation in culture (12 weeks), in vitro hardening was useful in improving the survival rate of tea plants (Table 2). The lowest survival of $46 \%$ was observed for 4 -week-old plants grown in $250 \mathrm{ml}$ flasks, whereas $94 \%$ survival was obtained after prolonged incubation in culture (12 weeks), i.e. following in vitro hardening. Generally in culture, except in a few cases, the diameter of the green microshoots used varied from 0.4 to $0.7 \mathrm{~mm}$, with $3-5$ leaves (Figure $1 d$ ). A previous study indicated that microshoots with green stems are most appropriate for obtaining rooting with almost $100 \%$ efficiency ${ }^{10}$.

During this experiment it was noticed that tissue cultureraised plants showed superior growth following prolonged incubation, and that such plants also achieved rapid secondary growth of stem resulting in relatively harder stems that may give better survival following transfer to soil. Generally plantlets took 8-10 weeks to establish in soil; which was evident from the appearance of new sprouts. The study indicates that simple modifications in culture conditions significantly improved the overall survival of in vitro propagated tea plantlets during lab-to-land transfer. The tissue culture-raised plants were morphologically similar, with normal leaf and growth.

Well-hardened plants were found to be healthy (Figure $2 a-c)$ and growth parameters like length of shoots, number of leaves, stem girth, etc. were seen to vary 


\section{RESEARCH COMMUNICATIONS}

Table 2. Effect of in vitro hardening on survival and growth performance of tissue culture-raised tea plants in nursery

\begin{tabular}{|c|c|c|c|c|}
\hline Parameters & $\begin{array}{c}\text { Four-week-old } \\
\text { plants grown in } 250 \mathrm{ml} \\
\text { conical flasks } \pm \mathrm{SE}\end{array}$ & $\begin{array}{l}\text { 12-week-old plants } \\
\text { grown in } 250 \mathrm{ml} \\
\text { conical flasks } \pm \mathrm{SE}\end{array}$ & $\begin{array}{l}\text { 12-week-old plants } \\
\text { grown in } 500 \mathrm{ml} \\
\text { conical flasks } \pm \mathrm{SE}\end{array}$ & LSD \\
\hline Survival of plants $(\%)^{*}$ & $46.00 \pm 2.19$ & $90 \pm 4.98$ & $94 \pm 3.58$ & 10.67 \\
\hline Increment in shoot length over initial value $(\mathrm{cm}) *$ & $1.92 \pm 0.19$ & $3.96 \pm 0.37$ & $4.04 \pm 0.21$ & 0.93 \\
\hline Increment in leaf number per plant over initial value & $3.4 \pm 0.22$ & $6.2 \pm 0.33$ & $6.8 \pm 0.52$ & 1.31 \\
\hline Leaf thickness $(\mu \mathrm{m})$ & $177.6 \pm 2.22$ & $182.0 \pm 3.15$ & $183.2 \pm 1.66$ & 8.34 \\
\hline Stomatal frequency & $534.8 \pm 4.79$ & $544.0 \pm 6.27$ & $561.6 \pm 5.58$ & 19.23 \\
\hline \multicolumn{5}{|l|}{ Stomata size } \\
\hline Length $(\mu \mathrm{m})$ & $38.8 \pm 1.56$ & $40.4 \pm 0.67$ & $39.6 \pm 0.67$ & 3.63 \\
\hline Width $(\mu \mathrm{m})$ & $30.6 \pm 0.83$ & $31.6 \pm 1.15$ & $30.8 \pm 0.87$ & 3.31 \\
\hline RWC of leaves $(\%)$ & $91.96 \pm 1.03$ & $91.87 \pm 0.93$ & $91.4 \pm 0.46$ & 2.92 \\
\hline Specific leaf mass & $4.88 \pm 0.07$ & $5.07 \pm 0.19$ & $4.92 \pm 0.04$ & 0.40 \\
\hline
\end{tabular}

*Each treatment consists of 50 rooted plants; data are recorded four months after transfer of tissue culture-raised plants to pots.

Each treatment consists of five replicates.

significantly between treatments. However, significant difference was not noticed for leaf thickness, stomata frequency and size, RWC and specific mass of leaves. These results suggest that in vitro-raised plantlets were appropriately hardened, stable as well as normal. After two and half years following transfer of in vitro-raised hardened plants to field, they grew satisfactorily and formed normal tea bushes (Figure $2 d$ ).

For decades micropropagation is being advocated as an efficient means for the improvement of tea and tea industry. However, the application of tissue culture technology for commercial-scale propagation of tea is still inadequate on account of problems like: (i) lack of reproducible regeneration system; (ii) difficulty in rooting of shoots in some tea clones, and (iii) acclimatization and successful field establishment of tissue culture-raised plants ${ }^{11}$. Due to these constraints the reported protocols for tea micropropagation have found only limited commercial success. This may be due to the fact that in vitroraised plantlets are normally cultured under conditions that provide slight/or no physiological stress. Availability of a carbon source (sucrose or other sugars) through the culture medium reduces the need for photosynthesis. In vitro-controlled aseptic environment eliminates the stress caused by microorganisms on transfer to ex vitro conditions. Therefore, in vitro produced plants need to properly acclimatize to survive when transferred to the field.

For in vitro micropropagation of plants, one of the most significant and essential steps is the period of transition at the time of hardening after transfer from in vitro laboratory condition to ex vitro environment. Due to heterotropic means of nutrition, lack of adaptation and exposure to the natural environment, during lab-to-land transfer micropropagated plants are first kept in the hardening chamber. At the time of hardening, micropropagated plants slowly adapt to the climatic conditions in the ex vitro environment, develop the ability to cope with the attack of various microorganisms and also develop functional photosynthetic machinery and other physiological systems required for survival after lab-to-land transfer $^{13,14}$. During the initial stages of hardening, wilting and desiccation are common ${ }^{3,15}$. As a result, mortality is high during transfer of micropropagated plants to the normal field conditions, as these plants have non-functional stomata, improper root system and feebly developed cuti$\mathrm{cle}^{16,17}$. To overcome these problems, several workers have conducted experiments by increasing gas and water vapour exchange utilizing permeable films, using growth retardents from trizol group to control/inhibit gibberellic acid $\left(\mathrm{GA}_{3}\right)$ biosynthesis, causing $\mathrm{CO}_{2}$ enrichment in the head space of the culture vessels by $\mathrm{CO}_{2}$ inflow, elevating irradiance in the incubation room, etc. ${ }^{17}$. These enhance autotrophy and growth in culture, ultimately improving survival of the micropropagated plantlets during transfer to soil in the greenhouse/nursery ${ }^{18}$. Therefore, observations based on the present study suggest that prolonged in vitro culture of plantlets for 12 weeks improves the overall physiological and anatomical maturity of micropropagated tea plantlets, resulting in improved survival during acclimatization and transfer to soil (up to 94\%).

In general, during hardening care is taken regarding various physical factors like temperature, intensity of light, air current, relative humidity in the air, atmospheric $\mathrm{CO}_{2}$ as well as other factors, like mineral nutrition, $\mathrm{pH}$ of soil and soil texture. Other significant aspects during acclimatization are the type, texture and ratio of potting material used. Soil $\mathrm{pH}$ is also critical and the soil should be selected carefully considering its suitability for the plant to be transferred. The soil contains various microand macroorganisms, among which some are beneficial and some are harmful for the growth of plants. Hence sterilized soil is often used initially. Several methods have been used for the hardening of tissue culture-raised plants during the early phase following transplantation ${ }^{8}$. 

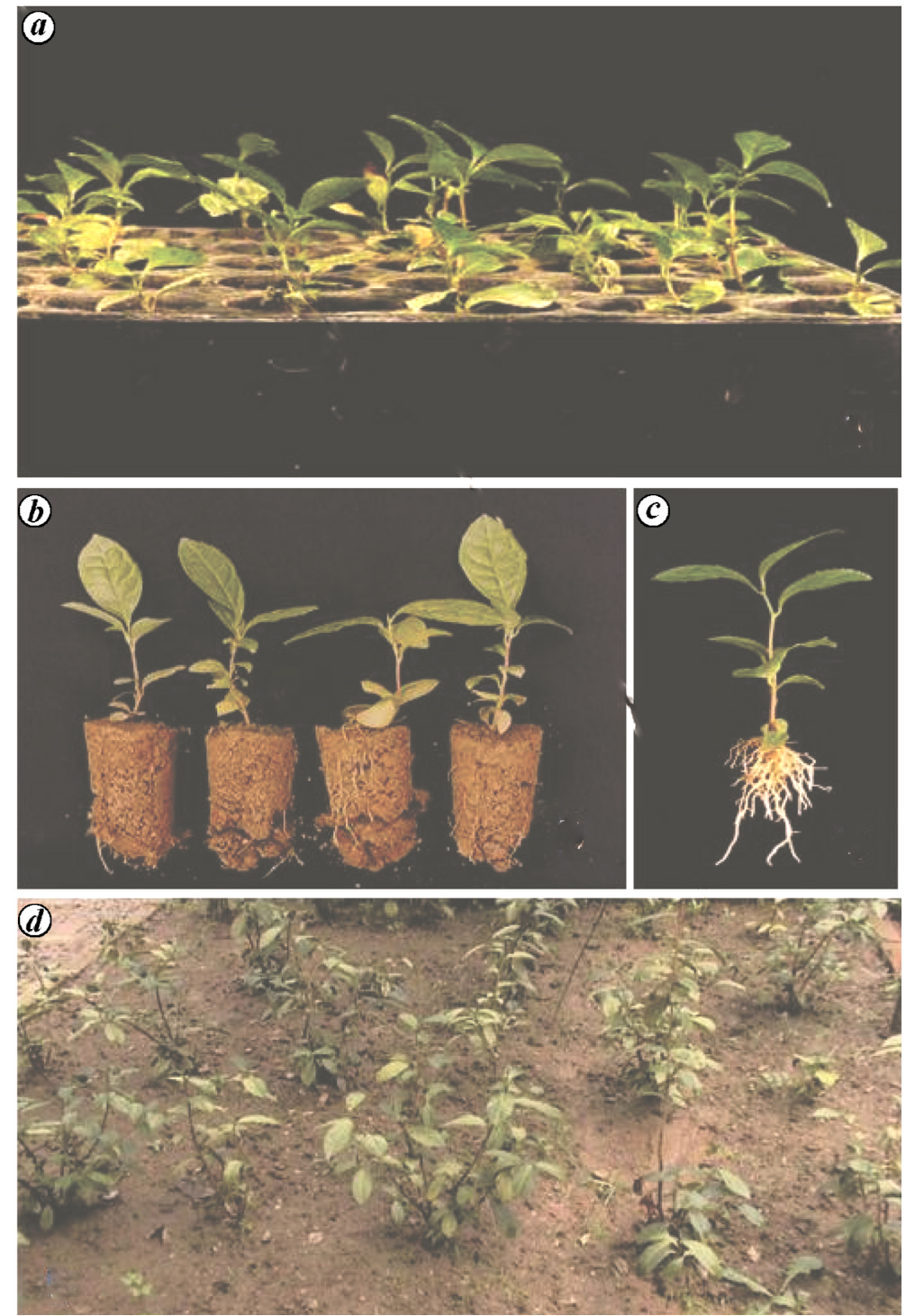

Figure 2. Field performance of in vitro-propagated tea plants. a-c, Four-month-old in vitro raised tea plants prior to field plantation. $\boldsymbol{d}$, In vitro-raised plants growing well in the field (photograph was taken two and half years after field plantation).

Yet the procedures used for acclimatisation such plants are not adequate for quality transplantation to the greenhouse or field ${ }^{3}$.

Other than various abiotic causes, a major cause contributing towards high mortality of the 'aseptically' raised plantlets are hasty exposure, particularly of the root system of these plants to microbial communities comprising beneficial microbes along with minor and major pathogens of soil. Plants propagated using tissue culture technique probably do not acquire sufficient resistance for protection against the microbial communities. As a result, a large number of such plants, immediately after transplantation or during the process of establishment, are attacked by soil microorganisms (mainly fungi) and do not survive. In an earlier study ${ }^{2}$, we had efficiently demonstrated that introduction of beneficial microorganisms having plant growth promotion ability and biocontrol properties against soil fungi may result in improved survival and establishment of tissue culture-raised plants.

Finally, interventions used in this study are simple, yet effective for acclimatization of micropropagated tea plants. Prolonged incubation period in culture to 12 weeks and use of larger culture vessel $(500 \mathrm{ml})$ proved to be helpful in enhancing the survival of tissue cultureraised tea plants. It is expected that in future the method will be useful and cost-effective during in vitro multiplication of several other plant species which face problems during lab-to-land transfer.

1. Bag, N., Palni, L. M. S., Chandra, S. and Nandi, S. K., Somatic embryogenesis in 'maggar' bamboo (Dendrocalamus hamiltonii) 
and field performance of regenerated plants. Curr. Sci., 2012, 102(9), 1279-1287.

2. Pandey, A., Palni, L. M. S. and Bag, N., Biological hardening of tissue culture raised tea plants through rhizosphere bacteria. Biotechnol. Lett., 2000, 22, 1087-1091.

3. Ziv, M., In vitro acclimatization. In Automation of Environmental Control in Plant Tissue Culture (eds Atiken-Christie J., Kozai, T. and Smith, M. L.), Kluwer, The Netherlands, 1995, pp. 493-516.

4. Bag, N., Palni, L. M. S. and Nandi, S. K., Mass propagation of tea using tissue culture methods. Physiol. Mol. Biol. Plants, 1997, 3, 99-103.

5. Kato, M., Regeneration of plants from tea stem callus. Jpn. J. Breed, 1985, 35, 317-322.

6. Akula, A. and Dood, W. A., Direct somatic embryogenesis in a selected teaclone, 'TRI-2025' (Camellia sinensi (L.) O. Kuntze) from nodal explants. Plant Cell Rep., 1998, 17, 804-809.

7. Wu, C. T., Studies on the tissue culture of tea plant. J. Agric. Assoc. China (Taiwan), 1976, 93, 30-42.

8. Banerjee, M. and Agarwal, B., In vitro rooting of tea (Camellia sinensis (L.) O. Kuntze). Indian J. Exp. Biol., 1990, 28(10), 936939.

9. Prakash, O., Sood, A., Sharma, M. and Ahuja, P. S., Grafting micropropagated tea (Camellia sinensis (L.) O. Kuntze) shoots on tea seedlings- a new approach to tea propagation. Plant Cell Rep., 1999, 18, 883-888.

10. Bag, N. and Palni, L. M. S., A two-step and highly reproducible procedure for in vitro rooting of micropropagated tea (Camellia sinensis L. (O) Kuntze) shoots. J. Hortic. Sci. Biotechnol., 2010, 85(3), 197-204.

11. Murashige, T. and Skoog, F., A revised medium for rapid growth and bioassays with tobacco tissue cultures. Physiol. Plant., 1962, 15, 473-497.

12. Bag, N., Chandra, S., Palni, L. M. S. and Nandi, S. K., Micrpropropagation of Dev-ringal (Thamnocalamus spathiflorus [(Trin.) Munro] - a temperate bamboo, and comparison of in vitro propagated plants and seedlings. Plant Sci., 2000, 156, 125-135.

13. Dhawan, V. and Bhojwani, S. S., Hardening in vitro and morphophysiological changes in the leaves during acclimatization of micropropagated plants of Leucaena leucocephela (Lam.) de Wit. Plant Sci., 1987, 53, 65-72.

14. Chandra, S., Bandopadhyay, R., Kumar, V. and Chandra, R., Acclimatization of tissue cultured plantlets: from laboratory to land. J. Biotechnol. Lett., 2010, 32, 199-1205.

15. Cappelades, M., Fontarnau, R., Carulla, C. and Debergh, P., Environment influences anatomy of stomata and epidermal cells in tissue cultured Rosa multiflora. J. Am. Soc. Hortic. Sci., 1990, 115, 141-145.

16. Sutter, E., Chemical composition of epicuticular wax in cabbage plants grown in vitro. Can. J. Bot., 1984, 62, 74-77.

17. Kozai, T., Kino, S., Jeong, B. R., Kinowaki, M., Ochiai, M., Hayashi, M. and Mori, K., A sideward lighting system using diffusive optical fibers for production of vigorous micropropagated plantlets. Acta Hortic., 1992, 319, 237-242.

18. Deb, C. R. and Imchen, T., An efficient in vitro hardening technique of tissue culture raised plants. Biotechnology, 2010, 9(1), 79-83.

ACKNOWLEDGEMENTS. N.B. thanks The World Green Tea Association, Shizuoka, Japan for award of O-Cha (Tea) Pioneer Academic Research Grant Program. We thank Department of Biotechnology, Government of India for financial support

Received 20 December 2018; accepted 20 February 2019

doi: $10.18520 / \mathrm{cs} / \mathrm{v} 117 / \mathrm{i} 2 / 288-293$

\section{Molecular phylogeography of Ficus benghalensis Linnaeus using nrDNA ITS 1, cpDNA trnL and cpDNA rps16 from the Indian subcontinent}

\author{
Sheetal Sharma ${ }^{1}$, Richa Mehra ${ }^{1}$ and Felix Bast ${ }^{2, *}$ \\ ${ }^{1}$ Department of Biosciences, and \\ ${ }^{2}$ Department of Plant Sciences, Central University of Punjab, \\ Bathinda 151 001, India
}

Ficus benghalensis Linnaeus (Moraceae) is the national tree of India and is well known for its pharmacological properties. The present study was aimed to determine the genetic diversity of $F$. benghalensis from the Indian subcontinent using sequence-based multi-locus phylogeography. A total of 20 geographical isolates were collected from different regions, covering major parts of its species range within the country. Sequence data from nuclear-encoded internal transcribed spacer region (ITS1), plastid-encoded trnL-F spacer region $(\operatorname{trnL})$ and ribosomal intron region (rps16) were generated. The trnL-based maximum likelihood phylogram revealed the existence of two haplotypes, whereas ITS1 and rps16-based maximum likelihood analysis did not reveal much variation for this species distributed in the Indian subcontinent. These results depict long-distance random gene flow across the subcontinent, and support the post-glacial population contraction events. To validate the impact of palaeo-historic climatic events on current geographic and genetic distribution, species distribution modelling-coupled phylogeography is suggested.

Keywords: Banyan, genetic heterogeneity, haplotypes, maximum likelihood, phylogeography.

FICUS Linn. (Moraceae) is one of the largest genera amongst angiosperms with around 1000 tree species native mainly to the world tropics. Fig trees (Ficus spp.) are considered to be the foundation species with major influence on community structure and ecosystem function, as they are often abundant and fruit throughout the year in many tropical forests ${ }^{1}$. Figs are exclusively pollinated by female agaonine wasps that lay their eggs in fig flowers, where wasp larvae thrive on the developing seeds ${ }^{2}$. This obligate mutualism is considered to be the basis for co-evolution of fig-wasp species over millions of years ${ }^{3}$. The short-lived (1-2 days) fig wasps are vulnerable to climate change and global warming may lead to their extinction in the near future ${ }^{4}$. Fig plants are the centre for complex web animals, including specialists and generalists, but are at major risk owing to the declining population of fig wasps, which will further affect many trophic levels.

*For correspondence. (e-mail: felix.bast@gmail.com) 